\title{
Trastuzumab and Cardiotoxicity
}

\author{
M. Fiuza and A. Magalhães \\ Hospital de Santa Maria, \\ University Clinic of Cardiology, Lisbon, \\ Portugal
}

\section{Introduction}

In the last two decades relevant improvements have been achieved in cancer therapy with a significant increase in overall survival. However these achievements have also been accompanied by a rise in the occurrence of side effects involving several organs, in particular the cardiovascular system. Indeed, the incidence of cardiotoxicity is continuously growing which can vanish the effectiveness of cancer therapy.

Breast cancer is the second most common form of cancer in women and the leading cause of death caused by malignancy. Over the past 25 years, breast cancer incidence has risen globally, with the highest rates in industrialized countries. However, the survival rate of cancer patients has greatly increased because of early detection through screening, as well as improvement in pharmacologic treatment. Women are, therefore, now living sufficiently long for delayed consequences of treatment to become increasingly evident.

Approximately 20-25\% of breast cancer overexpresses the human epidermal growth factor receptor II (HER-2). Amplification of HER-2 gene confers aggressive behavioral traits on breast cancer cells, including incresead growth and proliferation, enhanced invasiveness and metastatic capability. (Slamon, 1987)

HER-2 is a transmembrane tyrosine kinase receptor and a member of the epidermal growth factor receptor (EGFR) family, and regulate many important cell-type specific functions, particularly cell growth, proliferation and survival. (Slamon, 1987; Chien, 2006)

The use of trastuzumab (a humanized monoclonal antibody against HER-2 receptor) has changed the natural history of patients with HER-2 positive breast cancer. In the metastatic setting, the combination of trastuzumab plus chemotherapy has significantly improved survival, response rate, time to progression, and quality of life when compared with standard chemotherapy (Slamon 1987, 2001; Vogel, 2002). In the adjuvant setting, the use of trastuzumab decreased the risk of recurrence and death (Buzdar, 2005). Given these impressive results, trastuzumab has become the standard of care for treatment of patients with HER-2 positive breast cancer.

Although trastuzumab is devoid of the classical toxicities related with cancer treatment, one of major concerns noted is the occurrence of symptomatic and asymptomatic cardiac dysfunction. In fact, this treatment showed to be associated with an increased incidence of 
heart failure that ranged from $4.1 \%$ in the adjuvant setting to $27 \%$ in patients with metastatic disease who received concurrent anthracycline therapy (Perez E., 2004). Early identification of patients at risk for cardiotoxicity is a major challenge for both cardiologists and oncologists, for the definition of more tailored antineoplastic therapeutic interventions. The use of cardiac biomarkers such as BNP, N-terminal pro-BNP, and troponin I, has been suggested as a method for early detection of cardiotoxicity. Also, newer measurements of LV function such as strain, strain rate and speckle tracking may be sensitive tools to detect myocardial dysfunction before changes in EF are evident, possibly identifying at-risk patients at an earlier stage.

\section{Diagnosis and strategies}

\subsection{Clinical benefits of trastuzumab}

Based in substantial improvement achieved with trastuzumab in the trials performed, US Food and Drug Administration approved in 1998 this agent for the treatment of metastatic breast cancer. Indeed, in phase 2 trial was found an objective response in $12 \%$ of patients. (Baselga et al., 1996) These benefits were further confirmed in larger phase 2 and phase 3 trials (Cobleigh et al., 1999; Slamon et al., 2001). The phase 3 trial was design to compare a conventional chemotherapy regime with and without additional trastuzumab treatment. The data demonstrated that trastuzumab association to chemotherapy produced substantial response rate, improvement in time to disease progression, as well as reduction in 1-year mortality. (Slamon et al., 2001)

Since 2006 the use of trastuzumab has been extended to treat HER-2 positive early breast cancer patients. Five major randomized trials (Herceptin Adjuvant trial - HERA, National Surgical Adjuvant Breast and Bowel Project - NSABP B-31, North Central Cancer Treatment Group - NCCTG N9831, Breast Cancer International Research Group - BCIRG 006 and Finland Herceptin trial - FinHer) have proven the benefit of adjuvant trastuzumab in early breast cancer patients. More than 11000 patients were enrolled and treatment with trastuzumab led to about 50\% improvement in disease-free survival and 33\% improvement in overall survival. (Romond et al., 2005; Piccart-Gebhart et al., 2005; Tan-Chiu et al., 2005; Slamon et al., 2005; Joensuu et al., 2006).

Thus, concurrent treatment with trastuzumab is actually the standard of care for patients with early HER-2 positive breast cancer.

\subsection{What does cardiotoxicity mean?}

A precise definition of cardiotoxicity is still lacking. The Cardiac Review and Evaluation Committee supervising trastuzumab trials created a practical and easily applicable definition, which considered chemotherapy-induced cardiotoxicity as one or more of the following: 1) cardiomyopathy characterized by a decrease in LVEF, either global or more severe in the septum; 2) heart failure (HF) symptoms; 3) signs associated with HF, such as S3 gallop, tachycardia, edema; 4) decline in initial LVEF of at least $5 \%$ to less than $55 \%$ with accompanying signs or symptoms of $\mathrm{HF}$, or asymptomatic decrease in LVEF in the range of equal to or greater than $10 \%$ to less than $55 \%$ (Seidman, 2002). (Table 1) 
1. Cardiomyopathy characterized by a decrease in LVEF or changes of contraction most apparent in the interventricular septum

2. Heart failure symptoms

3. Signs associated with heart failure

4. Decline in initial LVEF of at least $5 \%$ to less than $55 \%$ with signs and symptoms of heart failure or asymptomatic decrease in LVEF of at least $10 \%$ to less than $55 \%$

Adapted from Seidman, et al. (2002). Cardiac dysfunction in the trastuzumab clinical trials experience. Journal of Clinical Oncology, Vol. 20, pp. 1215 - 1221

Table 1. Cardiac Review and Evaluation Committee criteria for the diagnosis of cardiac dysfunction

Cardiotoxicity can develop in a subacute, acute, or chronic manner:

a. Acute or subacute cardiotoxicity develop during the treatment period up to 2 weeks after therapy. It is characterized by electrocardiographic abnormalities such as QTintervals changes, ventricular repolarization abnormalities, supraventricular and ventricular arrhythmias or by acute heart failure, pericarditis, myocarditis or acute coronary syndromes.

b. Chronic cardiotoxicity is the most frequent and feared form. It can be divided in 2 groups according to the timing of symptoms onset: early, when occur in the first year after treatment and late when manifests more than 1 year after chemotherapy. The most common feature of chronic cardiotoxicity is asymptomatic systolic left ventricular dysfunction that can further lead to congestive HF. The incidence of this type of cardiotoxicity depends on several factors such as, total administered dose of chemotherapy, time of follow-up, age, history of previous cardiac disease, previous mediastinal radiation, as well as on the criteria used for cardiotoxicity assessment, ranging in different studies from $5 \%$ to $65 \%$ of patients. (Dolci, 2008; Pai, 2000).

The classic example of cardiotoxicity from anticancer treatment is anthracycline-related cardiomyopathy that remains the most common cardiotoxic chemotherapy agent. However many other agents can cause cardiotoxicity, namely the monoclonal antibody trastuzumab.

The development of chemotherapy-induced cardiomyopathy has significant implications. It has not only a negative impact on the cardiac outcome of cancer patients, but also limits their therapeutic options.

\subsection{Prevalence of trastuzumab induced-cardiomyopathy}

Cardiotoxicity was an unexpected finding in the phase 3 trials, as early clinical trials provided little or no indication of trastuzumab-induced cardiomyopathy. Although heart failure was seen in some patients enrolled in phase 2 trials, the rate of occurrence was low and patients were at increased risk due to previous anthracycline treatment. Subsequent reports of trastuzumab-related cardiotoxicity in the phase 3 combination chemotherapy trials prompted a retrospective analysis of seven phase 2 and 3 trastuzumab trials by an independent Cardiac Review and Evaluation Committee (CREC). (Seidman, Hudis, \& Pierri, 2002) An accurate assessment of cardiotoxicity in these trials has proved difficult because their design was different in what concerns the number of patients, definition of cardiotoxicity, analysis of end points and duration of follow-up. CREC used a new set of criteria to define cardiotoxicity (Table 1) and events were also classified by the New York 
Heart Association (NYHA) functional classification system. Data from 1219 patients enrolled in those 7 trials were retrospectively analyzed and cardiotoxicity was detected in 112 patients $(9.2 \%)$. The incidence of trastuzumab-induced cardiomyopathy ranged from $1 \%$ to $27 \%$ in different arms of trials and was higher when trastuzumab and anthracyclines were used concurrently (Seidman, Hudis, \& Pierri, 2002)(Table 2)

\begin{tabular}{lccccc}
\hline & \multicolumn{5}{c}{ Incidence (\%) } \\
\cline { 2 - 6 } Therapy & $\begin{array}{c}\text { Trastuzumab } \\
\text { monotherapy }\end{array}$ & Trastuzumab + AC & $\begin{array}{c}\text { Trastuzumab }+ \\
\text { paclitaxel }\end{array}$ & AC & $\begin{array}{c}\text { Paclitaxel } \\
\text { monotherapy }\end{array}$ \\
\hline CD & $3-7$ & 27 & 13 & 8 & 1 \\
NYHA class III or IV & $2-4$ & 16 & 2 & 4 & 1 \\
\hline
\end{tabular}

Adapted from Keefe DL (2002). Trastuzumab-associated cardiotoxicity. Cancer, Vol. 95, pp. 1592-1600 $\mathrm{AC}=$ anthracycline plus cyclophosphamide; $\mathrm{CD}=$ cardiac dysfunction; $N Y H A=$ New York Heart

Table 2. Retrospective analysis conducted by the Cardiac Review and Evaluation Committee of seven studies to detect trastuzumab-related cardiotoxicity.

Concerns about cardiotoxicity, together with the remarkable tumor response to this therapy, served as an impetus for several large trials collectively known as the trastuzumab adjuvant trials, which incorporate appropriate cardiac monitoring (Buzdar,2005; Perez, 2004; Cobleigh, 1999; Slamon 2001; Romond, 2005). The study protocol in these trials determined baseline assessment of LVEF using echocardiogram or myocardial scintigraphy and the exclusion of patients with impaired cardiac function, high doses of cumulative anthracycline exposure, and previous history of heart disease. Data from these trials are summarized in Table 3.

\begin{tabular}{|c|c|c|c|c|c|c|}
\hline Study and reference & Treatment arm & $\begin{array}{l}\text { Arm sample } \\
\text { size }\end{array}$ & $\begin{array}{l}\text { Median follow- } \\
\text { up (months) }\end{array}$ & $\begin{array}{l}\text { Baseline } \\
\text { LVEF (\%) }\end{array}$ & $\begin{array}{l}\text { Grade III/IV NYHA } \\
\text { heart failure (\%) }\end{array}$ & $\begin{array}{l}\text { Cardiac } \\
\text { deaths }(n)\end{array}$ \\
\hline \multirow{3}{*}{$\begin{array}{l}\text { NCCTG N9831 } \\
\text { Romond et al. }(2005)^{5} \\
\text { Baselga et al. }(2006)^{18} \\
\text { Perez et al. }(2005)^{20}\end{array}$} & $A C \rightarrow P$ & 819 & \multirow[t]{3}{*}{18} & \multirow[t]{3}{*}{$250^{\mathrm{a}}$} & 0 & 0 \\
\hline & $\mathrm{AC} \rightarrow \mathrm{P} \rightarrow \mathrm{H}$ & 981 & & & 2.2 & 1 \\
\hline & $\mathrm{AC} \rightarrow \mathrm{PH}$ & 814 & & & 3.3 & 1 \\
\hline \multirow{2}{*}{$\begin{array}{l}\text { NSABP B-31 } \\
\text { Romond et al. }(2005)^{5} \\
\text { Tan-Chiu et al. }(2005)^{6}\end{array}$} & $A C \rightarrow P$ & 1,024 & \multirow[t]{2}{*}{28.8} & \multirow[t]{2}{*}{$250^{a}$} & 0.8 & 1 \\
\hline & $\mathrm{AC} \rightarrow \mathrm{PH}$ & 1,019 & & & 4.1 & 0 \\
\hline \multirow{2}{*}{$\begin{array}{l}\text { HERA } \\
\text { Piccart-Gebhart et al. }(2005)^{15} \\
\text { Smith et al. }(2007)^{16}\end{array}$} & $\begin{array}{l}\text { Protocol specified } \\
\text { chemotherapy alone }\end{array}$ & 1,698 & \multirow[t]{2}{*}{23.5} & \multirow[t]{2}{*}{$255^{\circ}$} & 0 & 1 \\
\hline & $\begin{array}{l}\text { Protocol specified } \\
\text { chemotherapy } \rightarrow \mathrm{H}\end{array}$ & 1,703 & & & 0.6 & 0 \\
\hline \multirow{2}{*}{$\begin{array}{l}\text { FinHer } \\
\text { Joensuu et al. }(2006)^{40}\end{array}$} & Tor $V \rightarrow F E C$ & 116 & 35 & \multirow[t]{2}{*}{ NR } & $3^{d}$ & 0 \\
\hline & $\mathrm{HT}$ or $\mathrm{HV} \rightarrow \mathrm{FEC}$ & 116 & 37 & & $0^{d}$ & 0 \\
\hline \multirow{3}{*}{$\begin{array}{l}\text { BCIRG006 } \\
\text { Slamon et al. }(2006)^{19}\end{array}$} & $A C \rightarrow T$ & 1,073 & \multirow[t]{3}{*}{36} & \multirow[t]{3}{*}{$\geq 50^{c}$} & 0.3 & 0 \\
\hline & $\mathrm{AC} \rightarrow \mathrm{TH}$ & 1,074 & & & 1.8 & 0 \\
\hline & $\mathrm{TCH}$ & 1,075 & & & 0.3 & 0 \\
\hline \multirow{2}{*}{$\begin{array}{l}\text { E2198 } \\
\text { Sledge et al. }(2006)^{41}\end{array}$} & $\mathrm{PH} \rightarrow \mathrm{AC}$ & 115 & NR & \multirow[t]{2}{*}{$250^{c}$} & $2.6^{d}$ & 0 \\
\hline & $\mathrm{PH} \rightarrow \mathrm{AC} \rightarrow \mathrm{H}$ & 112 & NR & & $3.6^{\mathrm{d}}$ & 0 \\
\hline
\end{tabular}

Adapted form Popat \& Smith. (2008). Therapy insight: anthracyclines and trastuzumab - the optimal management of cardiotoxic side effects. Nature Clinical Practice, Vol. 5, pp. 324-335

Table 3. Summary of trastuzumab-induced cardiotoxicity from adjuvant trials.

In the combined analysis of NCCTG N9831 and NSABP B-31 trials (administration of trastuzumab concurrent with adjuvant taxanes after anthracycline chemotherapy), was 
found that trastuzumab was withdrawal before 52 weeks in $31.4 \%$ of patients treated. In $14.2 \%$ of them was due to asymptomatic LVEF decline and in $4.7 \%$ due to HF symptoms (Romond et al., 2005). The 3-year cumulative incidence of NYHA class III or IV HF or death from cardiac causes reported in N9831 trial was $2.9 \%$ in the trastuzumab group, compared to $0 \%$ in the control group. In B-31 trial this endpoint was detected in $4.1 \%$ in those treated with trastuzumab and $0.8 \%$ in the control group. Twenty-seven patients from the total of 31 women who developed trastuzumab-induced cardiomyopathy, were followed for at least 6 months and only 1 patient had persistent symptoms of heart failure. (Slamon, 2001) These results were subsequently analysed by an independent group of reviewers that constituted the Adjuvant Cardiac Review and Evaluation Committee (ACREC) (Seidman, 2002). This independent review confirmed earlier risk estimates by showing that the concurrent use of trastuzumab and anthracycline based chemotherapy, increased the rate of congestive heart failure (CHF) nearly four-fold, from $0.45 \%$ to $2.0 \%$, at a median follow-up of 1.9 and 2.0 years, respectively.

In HERA trial (Perez, 2004) was reported a smaller number of cardiac events compared with B-31 and N9831 studies. This trial is a three-group, randomized trial that compared 1 year or 2 years of trastuzumab with observation in women with HER-2 positive early breast cancer. The overall rate of trastuzumab withdrawal due to safety issues was $6.8 \%$, with $4 \%$ stopping the treatment due to cardiac issues. The rate of symptomatic CHF was $2 \%$ in the trastuzumab group and $0.2 \%$ in the control group, with NYHA class III or IV CHF occurring in $0.6 \%$ of patients receiving trastuzumab and $0 \%$ of the control group. An asymptomatic or mildly symptomatic decline in LVEF was seen in $7.4 \%$ of women on trastuzumab and $2.3 \%$ of controls (Perez, 2004; Seidman, 2002). The overall risk of severe CHF reported in HERA was lower than that in B-31 $(0.6 \%$ versus $4 \%)$ as was the proportion of patients who discontinued trastuzumab due to cardiac issues. The explanation for these differences is not clearly established, but we can speculate that it may be due to the longer interval between stopping anthracyclines and initiating trastuzumab or to the inclusion criteria that determined a LVEF $\geq 55 \%$ in HERA trial compared to 50\% for N9831/B-31 trials.

An aspect of interest in the BCIRG trial is that one arm of this study did not include concomitant or sequential therapy with anthracyclines. This fact permitted the assessment of the true effect of trastuzumab on the heart without having to adjust for previous anthracycline lesion, that otherwise interfere with interpretation of cardiotoxicity. The incidence of NYHA class III or class IV CHF was 5.1-fold greater in the anthracycline group than in the nonanthracycline arm $(1.96 \%$ versus $0.38 \%)$ and the number of patients with LVEF decline of more than $10 \%$ from baseline was $19 \%$ and $9 \%$, respectively.

\subsection{Mechanism of cardiotoxicity}

Cardiotoxicity came to the forefront of concerns over chemotherapy in the early 1970s, when was detected a cumulative dose-related cardiac dysfunction was detected related with anthracycline treatment.

This agent produces a cardiac dysfunction identified as type I, characterized by ultrastructural abnormalities, morphological cellular (vacuoles, myofibrillar disarray and dropout, necrosis) and heart (dilated cardiomyopathy) changes and subsequent clinical evident dysfunction. (Billingham, 1978; Lefrak, 1973; Billingham, 1978) It is dose-related and virtually irreversible. Described methods to minimize type I cardiotoxicity include prolonged 
infusional administration schedules (Legha, 1982) and use of the free-radical scavenger dexrazoxane (Swain, 2004). Additionally, liposomal delivery, are being studied liposomal delivery systems (Ewer, 2002 ) and less-toxic analogs and less toxic analogs are being study.

In contrast, type II cardiac dysfunction associated with trastuzumab therapy does not seem to cause any ultrastructural change, while a myocardial dysfunction under cardiac stress is present. (Ewer, 2005) Other specific features are: it seems not to be dose-related; it increases when trastuzumab is given concurrently with anthracyclines; it seems to be reversible; and normal cardiac function may be restored with medical management of heart failure (Seidman, 2002; Valero, 2004; Perez, 2004; Ewer, 2008). Table 4 compares type I and type II chemotherapy-related cardiac dysfunction.

Type I (myocardial damage)

\begin{tabular}{|c|c|c|}
\hline Characteristic agent & Doxorubicin & Trastuzumab \\
\hline $\begin{array}{l}\text { Clinical course, response to } \\
\text { CRCD therapy }\end{array}$ & $\begin{array}{l}\text { May stabilize, but underlying damage appears to be permanent } \\
\text { and irreversible; recurrence in months or years may be } \\
\text { related to sequential cardiac stress }\end{array}$ & $\begin{array}{l}\text { High likelihood of recovery (to or near baseline } \\
\text { cardiac status) in } 2-4 \text { months (reversible) }\end{array}$ \\
\hline Dose effects & Cumulative, dose related & Not dose related \\
\hline Mechanism & Free radical formation, oxidative stress/damage & Blocked ErbB2 signaling \\
\hline Ultrastructure & $\begin{array}{l}\text { Vacuoles; myofibrillar disarray and dropout; necrosis (changes } \\
\text { resolve over time) }\end{array}$ & No apparent ultra structural abnormalities \\
\hline Noninvasive cardiac testing & $\begin{array}{l}\text { Decreased ejection fraction by ultrasound or nuclear } \\
\text { determination: global decrease in wall motion }\end{array}$ & $\begin{array}{l}\text { Decreased ejection fraction by ultrasound or } \\
\text { nuclear determination: global decrease in wall } \\
\text { motion }\end{array}$ \\
\hline Effect of rechallenge & $\begin{array}{l}\text { High probability of recurrent dysfunction that is progressive, } \\
\text { may result in intractable heart failure and death }\end{array}$ & $\begin{array}{l}\text { Increasing evidence for the relative safety of } \\
\text { rechallenge; additional data needed }\end{array}$ \\
\hline Effect of late sequential stress & High likelihood of sequential stress related cardiac dysfunction & $\begin{array}{l}\text { Low likelihood of sequential stress-related cardiac } \\
\text { dysfunction }\end{array}$ \\
\hline
\end{tabular}

Reprinted from Ewer \& Lippman (2005).Type II chemotherapy-related cardiac dysfunction: time to recognize a new entity. Journal of Clinical Oncology, Vol. 23, pp. 2900-2902

Table 4. Chemotherapy-related cardiac dysfunction.

The mechanisms of type I and type II cardiac dysfunction are complex and distinct. Type I cardiotoxicity is due, predominantly to iron-based oxygen free-radical that induce oxidative stress on cardiac cells. These free radicals produce peroxidation of myocyte membranes and subsequent influx of intracellular calcium, accelerated degradation of key sarcomeric protein and disruption of new sarcomere protein synthesis. (Valero, 2004; Ewer, 2002)

The molecular basis of type II chemotherapy related cardiac dysfunction is beginning to be elucidated (Speyer, 2002; Crone, 2002; Ozcelik, 2002; Sawyer, 2002; Negro, 2004). The mechanism of trastuzumab induced cardiotoxicity involves, at least in part, the ErbB2 pathway. This agent binds to the extracellular domain of the HER-2 protein and thus blocks ErbB2 signalling required for the growth, repair, and survival of cardiac cells. (Negro, 2004) ErbB2 signalling is highly complex, involving multiple ligand classes, cell systems, and pathway interactions. Of those actions, activation of the transcription factor nuclear- $\kappa \mathrm{B}$ (NF-

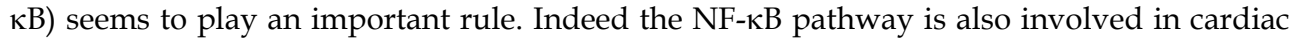
cells under stress, such as in myocardial infarction and hypertension and it seems to be essential in restoring the reperfusion after ischemia and also in reducing apoptosis. (Feldman, 2007).

Evidence supports a critical role for neuregulin 1 (NRG1) signalling through HER-2/HER-4 heterodimerization in cardiomyocyte survival pathways and maintenance of function. (Sawyer, 2002) NRG1 is produced by cardiac endothelial cells, binds HER-4 on 
cardiomyocytes and leads to heterodimerization with HER-2, with consequent activation of diverse intracellular signalling pathways, such as the PI3-kinase/AKT and MAP kinase pathways. Mouse models have given important contributes to these discovers. Mice with HER428 and NRG131 knockouts are both embryonically lethal.

Moreover, the essential role of HER-2 in maintenance of cardiac contractile function and structure and the possible protective effect provided by HER-2 was shown in a mouse model with a cardiac-restricted conditional HER-2 deletion mutant. Indeed, these mice stayed alive, but developed a dilated cardiomyopathy. (Negro, 2004; Crone, 2002; Ozcelik, 2002) This model provided support to the hypothesis that cardiac lesion related to trastuzumab is the result of direct targeting and inhibition of the HER-2 receptor, rather than immune-mediated or non-cardiac effects. Additionally, these mice were also sensitized to develop an anthracycline-induced cardiac dysfunction reflecting that seen clinically.

Inhibition of the previous described pathways after an insult such as anthracycline treatment could thus interfere with the heart's repair mechanisms. Indeed, de Kort et al. (2007) showed that myocardial HER-2 is upregulated in humans shortly after anthracycline exposure, providing support for the vulnerable-window hypothesis. (Fig 1.)

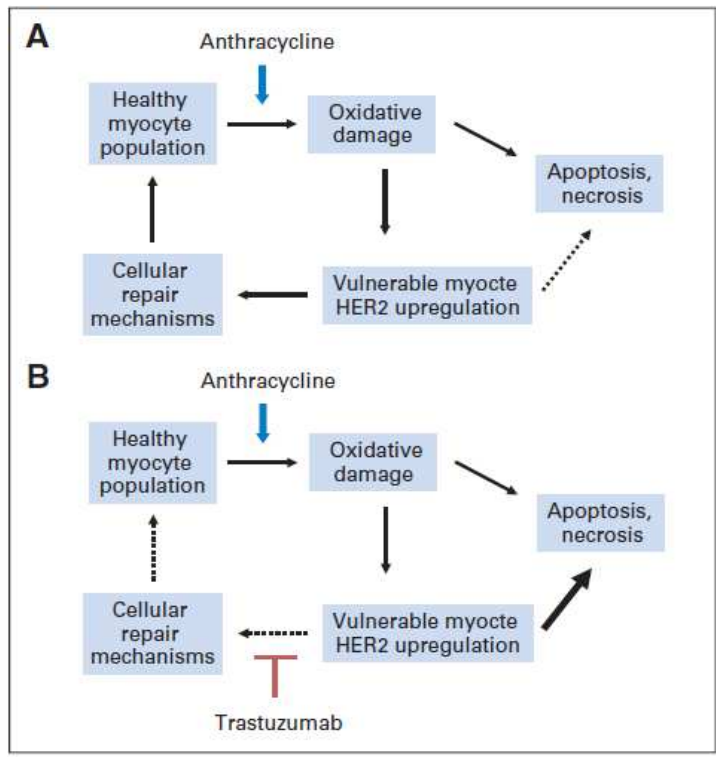

Reprinted from Ewer, M. (2010). Troponin I Provides Insight Into Cardiotoxicity and the AnthracyclineTrastuzumab Interaction. Journal of Clinical Oncology, Vol. 28, No. 25, pp 3901-3909

Fig. 1. (A) Simplified flow diagram of myocyte injury after anthracycline administration. Cell death is preceded by a period of vulnerability during which cell repair may take place. (B) The addition of trastuzumab inhibits cell repair compounding the loss of cardiac myocytes. HER2= human epidermal growth factor receptor 2 .

Although inhibition of HER-2 signalling seems to be a central mechanism of trastuzumabrelated cardiomyopathy, the pathophysiologic mechanism is likely more complex. Indeed 
early clinical results with lapatinib, an oral tyrosine kinase inhibitor, show minimal cardiotoxicity. (Geyer, 2006) Actually the explanation for this paradox is not sufficiently clear and remains an area of intense investigation. It is suggested that the difference between the two drugs may be explained by trastuzumab effect on adenosine triphosphate (ATP) depletion. Cardiac cells need an important quantity of ATP molecules and thus an agent that interferes with mitochondrial activity has the potential of alter normal myocyte function by decreasing the energy source. (Menendez, 2007) The binding between erbB2 and a specific antibody can unbalance $\mathrm{BCL}-\mathrm{X}_{\mathrm{L}} / \mathrm{BCL}-\mathrm{X}_{\mathrm{S}}$, leading to depolarization of the mitochondrial membrane potential, with reduction of ATP and subsequent alteration of contractility (Force, 2007).

\subsection{Risk factors}

The most established risk factors for the development of trastuzumab-induced cardiotoxicity are age $>50$ years and concurrent or prior exposure to anthracycline chemotherapy (Perez, 2004; Pinder, 2007). Based on data of the NSABP B-31 trial (Tan-Chiu, et al., 2005), baseline LVEF < 55\% and post-chemotherapy LVEF < 55\% were also considered as significant risk factors. Current or previous treatment with antihypertensive medication and a body mass index (BMI) $>25$ have been shown to increase the risk of cardiotoxicity in some trials, but the results are not uniform or consistent. Prior radiotherapy to a left-sided breast cancer, race or history of smoking were not associated to a increased risk of cardiac toxicity during trastuzumab treatment.

One important aspect is that clinical trials are limited to women under 65 years old and with a good performance status (Hutchins, 1999). Thus, trastuzumab safety data only apply to a relatively young and healthy group of patients. As the incidence of cancer increases greatly with age and more than $70 \%$ of all newly diagnosed cancers are in patients $>65$ years, information about efficacy and safety of chemotherapy is needed in this population. This was the impetus of a recent study by C. Serrano et al (Serrano, 2011) that intended to assess the cardiac safety profile and potential cardiac risk factors associated with trastuzumab in breast cancer patients $>70$ years. The records of forty-five women between the ages of 70 and 92 were evaluated and was found a significantly increased incidence of cardiac events among patients with a history of cardiac disease (heart failure, arrhythmias, myocardial ischemia, or valvular heart disease) and diabetes. The overall incidence of cardiac events was $26.7 \%$, and in $8.9 \%$ of them it was clinically evident. Thirty-three percent of women with known history of heart disease developed either asymptomatic or symptomatic cardiotoxicity compared to $9.1 \%$ with no previous cardiac disease $(\mathrm{p}=0.01)$. Additionally, $33.3 \%$ of diabetic women developed cardiac dysfunction compared to only $6.1 \%$ without diabetes. However, it is important to be cautious when interpreting these data given the small sample size and the very limited power to detect small differences in multivariate analysis.

In patients being simultaneous treated with anthracyclines and trastuzumab the probability of develop cardiotoxicity increases after a cumulative dose of doxorubicin superior to 300 $\mathrm{mg} / \mathrm{m}^{2}$ (Perez, 2004). The sequence in which chemotherapy agents are administered seem to influence the development of cardiac dysfunction. When anthracyclines and trastuzumab were administered simultaneously, the incidence of NYHA class III or IV HF was $16 \%$. (Slamon, 2001). The interval between administration of anthracycline and trastuzumab was about 3 weeks in the NSABP B-31 and BCIRG 006 trials, and it was showed an incidence of 
class III or IV CHF of $4.1 \%$ and $1.9 \%$, respectively (Romond 2005). This interval was larger in HERA trial, being approximately 3 months, and was found an incidence of cardiac dysfunction of $0.6 \%$, similar to that obtained in the nonanthracycline arm of the BCIRG 006 trial (0.4\%). (Piccart-Gebhart, 2005; Tan-Chiu, 2005; Joensuu, 2006) Thus, it seems that the greater the interval between treatment with these two drugs, the less cardiotoxicity is found. (Ewer, 2009) (Fig. 2)

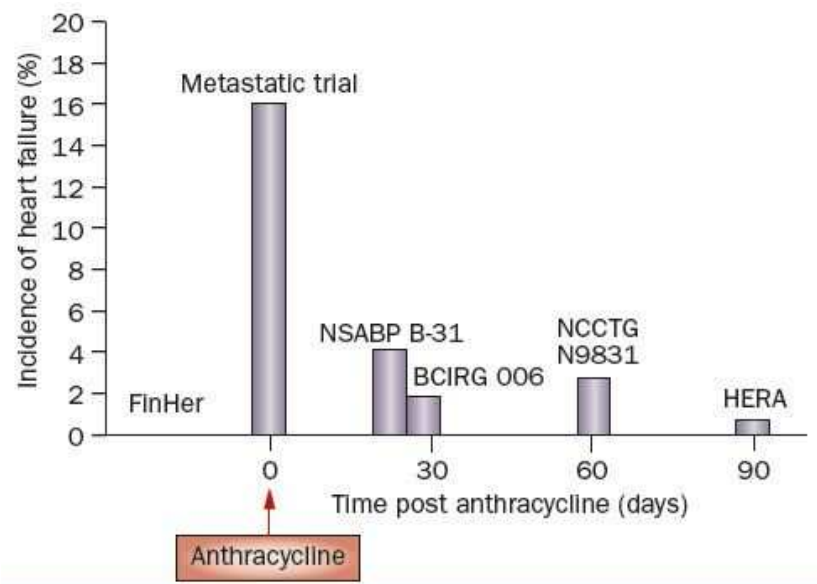

Reprinted from Nat. Rev Cardiovasc Med @2010 Nature Publishing

Fig. 2. Incidence of heart failure in the different trials in what concern timing post anthracycline treatment

\subsection{Clinical course}

Current data on trastuzumab-induced cardiomyopathy suggest that either symptomatic or asymptomatic LVEF decline has potential to recover by stopping the agent and introducing medical therapy for HF.

In the CREC review (Seidman, 2002) of the 112 patients who developed cardiotoxicity, 79\% responded to HF therapies. Further evidence of this phenomenon comes from MD Anderson series (Guarneri, 2006). In patients who developed symptomatic CHF, 79\% recover after discontinuation of trastuzumab and with appropriate treatment. Of note, one patient recovered quickly with cardiac therapy during treatment with trastuzumab and one died of progressive CHF.

In those patients with asymptomatic decline of LVEF, trastuzumab was stopped in $41 \%$. Recovery of LVEF was observed in $89 \%$ of women, independently of HF treatment. For the remainder who continued trastuzumab, LVEF recovered in $75 \%$ of patients.

Ewer et al (2005) published an observational study of 38 patients with trastuzumab-related cardiotoxicity. Thirty-one patients discontinued the agent and were treated with HF therapies. In all of them LVEF returned to baseline over a period of months (mean time: 1.5 months). In six women who stopped trastuzumab, but were not receiving HF treatment, 2 had persistent LV dysfunction during the 6 months follow-up. Trastuzumab was not 
withdrawal in one patient, despite evidence of cardiotoxicity, and after initiation of HF therapy was demonstrated a slight increase of LVEF. In a subgroup of patients (Ewer, 2002) treated with the maximum-tolerated doses of angiotensin converting enzyme inhibitors and beta-blockers, which had a full recovery of LVEF and had stable CHF, trastuzumab was reintroduced. The median duration of trastuzumab therapy was 8.4 months. In $88 \%$ of women (Ewer, 2005) LVEF remained stable and without recurrences of CHF; in the remainder, LVEF deteriorated and CHF reoccurred, necessitating permanent trastuzumab withdrawal. (Fig. 3) None of the patients died due to cardiac disease, and only one patient needed to be hospitalized because of CHF with volume overload.

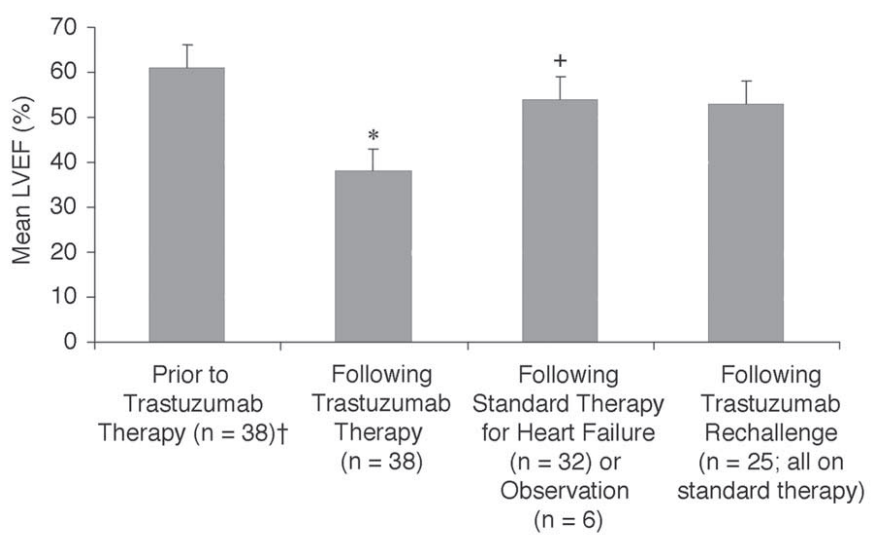

Reprinted from Ewer et al. (2005) Reversibility of trastuzumab related cardiotoxicity: new insights based on clinical course and response to medical treatment. Journal of Clinical Oncology, Vol. 23, pp. $7820-7826$

Fig. 3. Changes in left ventricular ejection fraction from baseline to re-treatment with trastuzumab $\left.{ }^{*}\right) \mathrm{P}<0.05$ versus before trastuzumab therapy. $(+) \mathrm{P}<0.05$ versus after trastuzumab therapy.

Similar results were obtained in trastuzumab adjuvant trials. In B-31 (Tan-Chiu et al. 2005) the majority of patients who developed cardiac dysfunction recovered completely $(55.5 \%)$ or partially $(30.6 \%)$, as in HERA trial (Piccart-Gebhart, 2005) were there was $81 \%$ of recovery.

Although current data is limited regarding the potential long-term effects of trastuzumab on cardiac function, actual evidence of trastuzumab-induced cardiotoxicity should be evaluated in the context of the improvements in disease-free survival, response rate and quality of life attributable to trastuzumab therapy. (Table 5) Thus efforts should be placed on close cardiac function monitoring and development of strategies to early diagnosis.

\subsection{Monitoring of cardiotoxicity}

Outside the trials, the best cardiac monitoring strategy remains undefined. The British Society of Echocardiography (Fox, 2006) and more recently the European Society for Medical Oncology (Bovelli et al., 2010), issued a statement regarding the cardiac monitoring of patients proposed to receive trastuzumab. Clinical evaluation and assessment of cardiovascular risk factors and comorbidities should be performed to all women prior the initiation of this agent. 


\begin{tabular}{|c|c|c|c|c|c|c|c|c|c|c|c|}
\hline \multirow{2}{*}{$\begin{array}{l}\text { Study and } \\
\text { Treatment }\end{array}$} & \multirow{2}{*}{$\begin{array}{l}\text { No. of } \\
\text { Evaluated } \\
\text { Patients }\end{array}$} & \multirow{2}{*}{$\begin{array}{c}\text { Absolute } \\
\text { DFS } \\
\text { Benefit } \\
\text { of Tras at } \\
3 \text { Years } \\
(\%)\end{array}$} & \multicolumn{2}{|r|}{ DFS } & \multirow{2}{*}{$\begin{array}{l}\text { Cardiac Event } \\
\text { Rate per Study } \\
\text { Protocol }(\%)\end{array}$} & \multirow{2}{*}{$\begin{array}{c}\text { Cardiac } \\
\text { Event Rate- } \\
\text { Independent } \\
\text { Review }(\%)\end{array}$} & \multirow{2}{*}{$\begin{array}{c}\text { Recovery } \\
\text { Rate from } \\
\text { Cardiac- } \\
\text { Independent } \\
\text { Review }(\%)\end{array}$} & \multirow{2}{*}{$\begin{array}{c}\text { Absolute OS } \\
\text { Benefit of } \\
\text { Tras at } 3 \\
\text { Years }(\%)\end{array}$} & \multicolumn{2}{|r|}{ OS } & \multirow{2}{*}{$\begin{array}{c}\text { Cardiac } \\
\text { Death- } \\
\text { Independent } \\
\text { Review }(\%)\end{array}$} \\
\hline & & & $\mathrm{HR}$ & $95 \% \mathrm{Cl}$ & & & & & HR & $95 \% \mathrm{Cl}$ & \\
\hline \multicolumn{12}{|l|}{ B-31 + N98315,10,11,15 } \\
\hline $\mathrm{AC} \rightarrow \mathrm{Pac}$ & 1,775 & & & & $0.3-0.9$ & 0.5 & 43 & & & & 0.11 \\
\hline $\mathrm{AC} \rightarrow \mathrm{Pac}+$ Tras & 1,799 & 12 & 0.48 & 0.39 to 0.59 & $3.3-3.8$ & 2.0 & 86 & 3 & 0.67 & 0.48 to 0.93 & $0.17 t$ \\
\hline \multicolumn{12}{|l|}{ HERA $^{12,13,13 a}$} \\
\hline $\begin{array}{l}\text { Anthracycline-based } \\
\text { chemo* }\end{array}$ & 1,698 & & & & 0.6 & 0.7 & & & & & 0.1 \\
\hline $\begin{array}{c}\text { Anthracycline-based } \\
\text { chemo }+ \text { Tras }^{*}\end{array}$ & 1,703 & 6 & 0.64 & 0.54 to 0.76 & 3.6 & 4.3 & 81 & 3 & 0.66 & 0.47 to 0.91 & 0 \\
\hline \multicolumn{12}{|l|}{ FinHer ${ }^{3}$} \\
\hline $\begin{array}{l}\text { Anthracycline-based } \\
\text { chemo }\end{array}$ & 116 & & & & 1.7 & & & & & & 0 \\
\hline $\begin{array}{c}\text { Anthracycline-based } \\
\text { chemo + Tras }\end{array}$ & 116 & 13 & 0.65 & 0.38 to 1.12 & 0.9 & & & 5 & 0.55 & 0.27 to 1.11 & 0 \\
\hline \multicolumn{12}{|l|}{ BCIRG $006^{6,6 a}$} \\
\hline $\mathrm{AC} \rightarrow \mathrm{Doc}$ & 1,073 & & & & 0.7 & & & & & & 0 \\
\hline $\mathrm{AC} \rightarrow \mathrm{Doc}+$ Tras & 1,074 & 6 & 0.64 & 0.53 to 0.78 & 2.0 & & & 4 & 0.63 & 0.48 to 0.81 & 0 \\
\hline TCH (Doc, Carb, Tras) & 1,075 & 5 & 0.75 & 0.63 to 0.90 & 0.4 & & & 2 & 0.77 & 0.60 to 0.99 & 0 \\
\hline
\end{tabular}

Reprinted from Patrick G. et al (2010). Trastuzumab-Related Cardiotoxicity Following AnthracyclineBased Adjuvant chemotherapy: How Worried Should We Be? Journal of Clinical Oncology, Vol 28 , No. 21, pp 3407-3410

Table 5. Long-term cardiac risk.benefit analysis of trastuzumab-based adjuvant chemotherapy.

The statements specified that LV function must be assessed before treatment and at 3-month intervals during the administration of trastuzumab.

Echocardiography is the recommended method for evaluating LV function. (Bovelli et al., 2010) Among the imaging techniques, echocardiography has multiple advantages as it is easily accessible, with no radiation exposure and can assess LV systolic and diastolic dysfunction, heart valve disease, pericarditis and pericardial effusion.

LVEF is the most frequent parameter used for evaluation of cardiac function before initiating chemotherapy and a value less than $54 \%$ is considered a risk factor for subsequent development of HF. Extreme caution during consecutive assessment of LVEF is fundamental, in order to diminish the intra and interobserver variability. The use of 3dimensional echocardiography or administration of contrast for left ventricle opacification can be useful strategies to achieve this proposal. However, LVEF is not a sensitive index to detect early systolic cardiac dysfunction. (Bovelli et al., 2010) Other echocardiographic techniques such as Doppler-derived parameters seem to show early changes in myocardial function in this setting. (Hare, 2009; Fallah-Rad, 2008).

Myocardial scintigraphy provides a very reliable measurement of LVEF, however does not allow evaluation of regional myocardial kinetic or diastolic function, which can be important aspects of cardiotoxicity. Additionally, it has the disadvantage of radiation exposure.

Cardiac magnetic resonance imaging (MRI) is the gold standard for accurate assessment of LV volumes and LVEF, and also allows evaluation of myocardial perfusion and tissue characterization. The common feature of trastuzumab-induced cardiotoxicity is increase of LV volumes, decrease in LVEF and delayed enhancement within the mid-myocardium portion of LV (Fallah-Rad et al., 2008). MRI has already been validated for LV function monitoring in patients treated with trastuzumab, however, due to its high cost and limited availability, it can not be used as screening test. 
In this field, for an accurate monitoring oncologists and cardiologists should work as a team and prompt multidisciplinary approach to patient care, in order to detect damage caused by chemotherapy and achieve a positive resolution.

\subsection{Importance of early diagnosis of trastuzumab-related cardiotoxicity}

Identification of patients who will develop heart failure as a result of trastuzumab treatment remains an ongoing challenge. Currently, clinical examination and consecutive LVEF measurements have been used to determine the cardiac toxicity of chemotherapy. However, it has important limitations, namely the fact that a decline of LVEF represents a relatively late stage of cardiac dysfunction. Earlier detection of subclinical cardiac damage could lead to identifying, intervening, and possibly preventing late adverse cardiac outcomes. In the setting of trastuzumab-induced cardiotoxicity, it could allow to identify patients at higher risk that could benefit from prophylactic therapy, and also identify those who may recover from cardiac dysfunction and thus, not discontinued indiscriminately trastuzumab therapy depriving most patients from drug's effectiveness.

There is an intense research in this area, especially in what concern the role of cardiac biomarkers and new echocardiographic techniques.

\subsubsection{The role of new echocardiographic techniques}

Two dimensional evaluation of LVEF constitutes the most common way to assess cardiac function in chemotherapy-induced cardiomyopathy, but it has some limitations, namely low reproducibility and dependence of hemodynamic conditions.

Myocardial strain and strain rate (SR) are newer echocardiographic techniques for evaluation of LV function, offering sensitive measurement of myocardial deformation, and seem to be able to identify subclinical dysfunction in various settings, before impairment of LVEF becomes evident. (Geyer et al., 2010). These parameters can be assessed by tissue Doppler imaging (TDI) or more recently, by speckle tracking (ST).

TDI uses Doppler principles to quantify tissue-derived signals, enabling a quantitative analysis of systo-diastolic function in terms of global, regional, segmental and parietal function. Strain and SR assessed by TDI are pulsed Doppler measurements with spatial integration, obtained by determination of myocardial parietal displacement, taking into account the linear distance between the two points. (Ho \& Solomon, 2006).

Speckle tracking is a distinct method to evaluate global and regional LV function. It's not Doppler based and thus, allow assessment of strain and SR independently of angle, a limitation of TDI. An important feature of this technique is the possibility of assessing longitudinal, radial and circumferential LV deformation in a single acquisition. Additionally, it is simple to perform, the processing can be done subsequently offline and has a reduced intra and interobserver variability (Geyer et al., 2010).

These echocardiographic techniques have been evaluated in murine models of chemotherapy-related cardiotoxicity and more recently, in patients with anthracyclineinduced cardiomyopathy. (Neilan et al, 2006; Jassal et al, 2009)

Recently some research has been done to elucidate the role of these imaging techniques in subclinical detection of trastuzumab-induced cardiotoxicity. 
Hare et al. (2009) studied 35 women treated with trastuzumab in the adjuvant and metastatic setting. LVEF measured either by 2D and 3D echocardiography, as well as myocardial E-velocity, did not demonstrate significant change in the patients evaluated. However, a reduction in longitudinal SR at 3 months after trastuzumab administration was detected in 18 patients. (Fig. 4) Three of them had a subsequent decrease in LVEF and another 2 patients showed a decline in LVEF within 20 months of follow-up. Data from this study suggest SR to be a parameter able to identify early impairment of cardiac function in trastuzumab-induced cardiomyopathy setting.
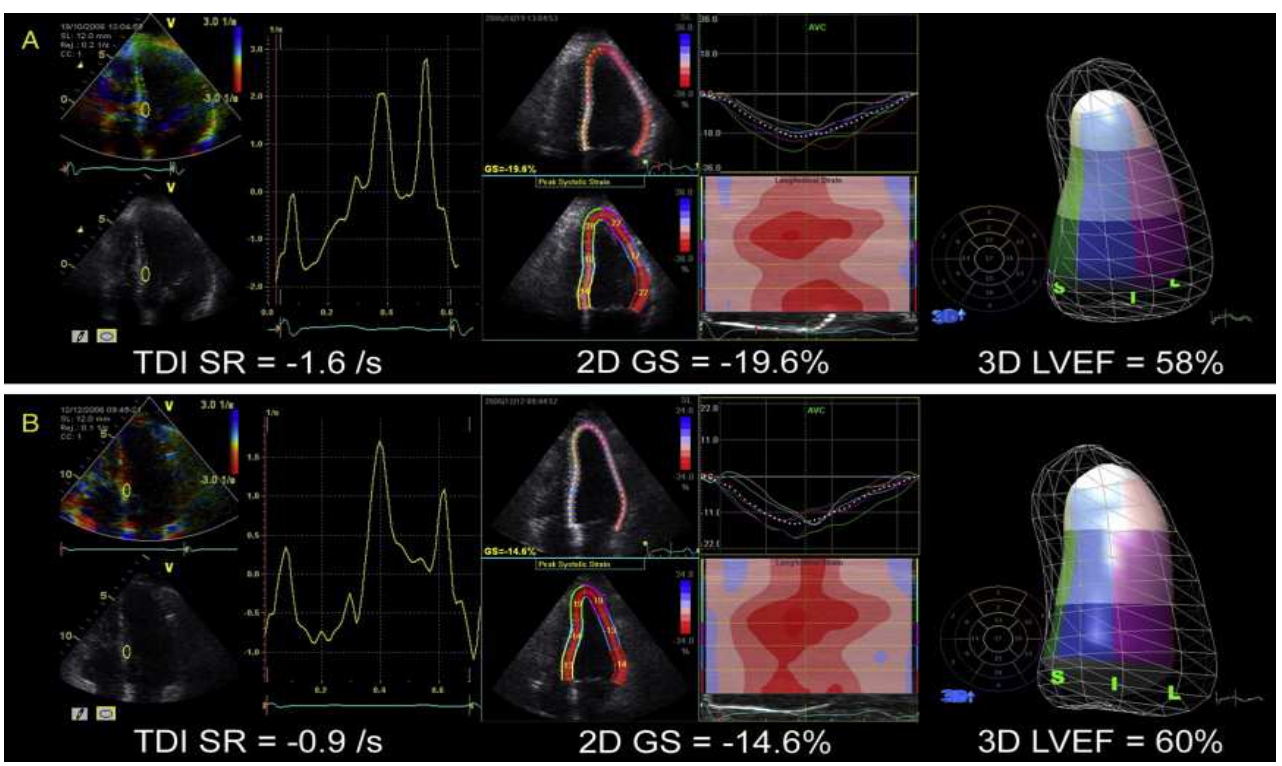

Reprinted from Hare, J. et al (2009). Natasha Woodward, Thomas H. Marwick Use of myocardial deformation imaging to detect preclinical myocardial dysfunction before conventional measures in patients undergoing breast cancer treatment with trastuzumab. American Heart Journal, Vol. 158, No. 2, pp. 294-301

Fig. 4. Example of preclinical reduction in myocardial deformation. Reductions in TDI SR and 2D speckle-tracking strain from initial echocardiogram (A) over 2 months during therapy with trastuzumab (B), with no concomitant reduction in 3D LVEF in a patient who ceased trastuzumab for symptoms consistent with myocardial dysfunction. GS, Global strain.

The study published by Fallah et al. (2011) showed similar results. Indeed it was found that an early reduction in TDI and strain values was subsequently followed by a significant decline of LVEF. Forty two patients were studied and 10 of them developed cardiac dysfunction, necessitating withdrawal of trastuzumab. There weren't significant differences in baseline TDI and strain parameters between patients who developed cardiotoxicity and those who maintain normal LVEF measurements. However, at 3 months after initiation of therapy was found a significant decrease in lateral $S^{\prime}$ value in patients who developed cardiac dysfunction, as well as a reduction in peak global longitudinal and radial strain. Although LVEF was normal at 3 months, TDI and strain measurements were reduced in all 10 patients who demonstrated an impairment of LVEF at 6 months follow up. 
A possible explanation for the increased sensitivity of strain in early detection of chemotherapy-induce cardiotoxicity can be a preferential regional pattern of damage, such that normal myocardial segments compensate the impaired function of the other, leading to a preserved LVEF.

TDI and speckle tracking imaging are thus, very promissory tools for early detection of LV systolic dysfunction in trastuzumab treated patients.

\subsubsection{The role of biomarkers}

Troponin I (TNI) has high sensibility and specificity to detect myocardial ischemia. Raised levels have been found after anthracycline administration and seem to predict subsequent cardiac morbidity and mortality. Indeed, Cardinale et al. 2004) showed that detectable TNI after high-dose chemotherapy is a predictor of LVEF impairment and higher rate of major cardiac events, especially in women who maintain elevation of TNI for more than a month (Fig.5).

In addition, they reported a high negative predictive value for TNI (99\%), which is important to identify low-risk patients who probably don't need close monitoring after treatment.

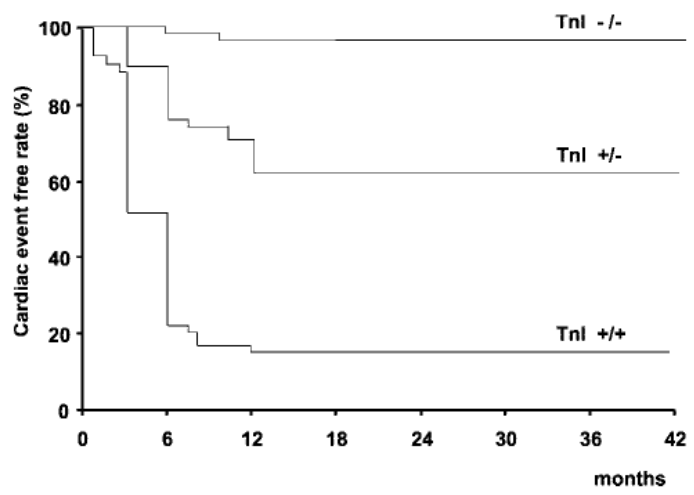

Reprinted from Cardinale, D. et al. (2004). Prognostic Value of Troponin I in Cardiac Risk Stratification of Cancer Patients Undergoing High-Dose Chemotherapy. Circulation, Vol. 109, pp. 2749-2754

Fig. 5. Cumulative cardiac events rate in 3 study groups. $\mathrm{P}<0.001$ for $\mathrm{TnI}{ }^{+/+} \mathrm{vs} \mathrm{TnI}^{-/-}$and $\mathrm{TnI}^{+/-}$, and for $\mathrm{TnI}+/-$ vs $\mathrm{TnI}^{-} /$-

The role of TNI in the clinical setting of trastuzumab-induced cardiotoxicity was recently assessed by Cardinale et al. (2010). A substantial finding of the study was that TNI assessment permits to detect patients more likely to developed LVEF impairment and to identify those who are less prone to recover. Indeed, trastuzumab-induced cardiotoxicity was detected in $72 \%$ of those who had elevation of TNI and in $7 \%$ of patients with normal TNI. From those who developed cardiac dysfunction, $60 \%$ recovered. The patients, whom LVEF did not return to baseline values had previous elevation of TNI, and additionally was found that this subgroup had a higher rate of cardiac events along the follow up (Fig.6). Interestingly, in those women with normal TNI who developed trastuzumab-related cardiotoxicity, was observed a subsequent normalization of LVEF and a lower rate of major 
cardiac events. These data are consistent with the hypothesis that a normal TNI value can predict LVEF recovery.

Additionally, the rate of major cardiac events, and thus increased morbidity, was higher in the patients who showed elevation of TNI.

Can be inferred that TNI permit to divide patients in two subgroups: those with good outcome, from those more prone to adverse events in whom close surveillance and prevention of further cardiotoxicity is needed.

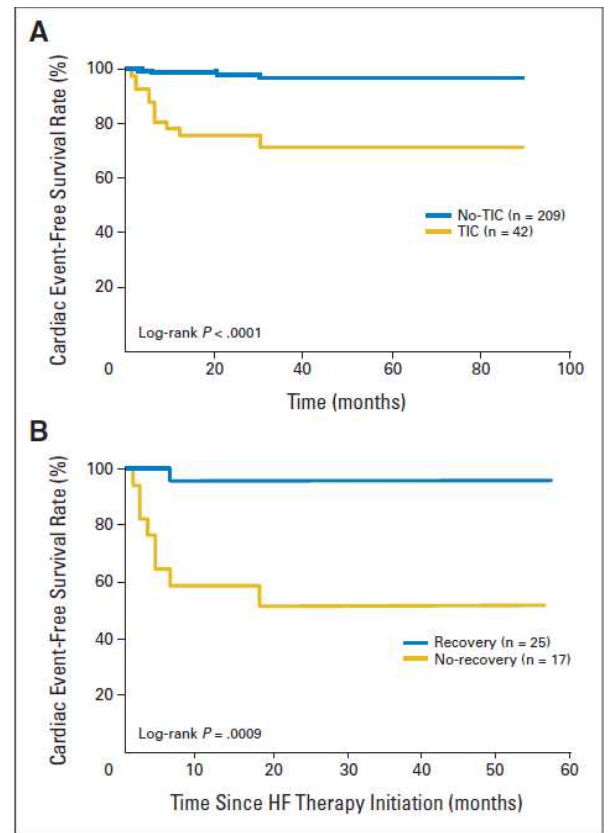

Reprinted from: Cardinale et al. (2010). Trastuzumab-Induced Cardiotoxicity: Clinical and Prognostic Implications of Troponin I Evaluation. Journal of Clinical Oncology, Vol. 28, No. 25, pp. 3910-3916

Fig. 6. (A) Kaplan-Meier curve of time to first cardiac event in patients developing trastuzumab-induced cardiotoxicity (TIC) and in patients who did not (No TIC). (B) Cumulative major adverse cardiac events in patients who recovered from cardiac dysfunction (Recovery) and in those who did not (No-recovery). Time zero refers to detection of cardiotoxicity and start of heart failure (HF) therapy.

Other studies such as the one published by Sawaya et al. (2011) showed similar results. Indeed an elevated TNI at three months predicted cardiac dysfunction at six months, as these patients were nine times more prone to developed cardiotoxicity than those with normal TNI values.

B-type natriuretic peptide (BNP) is a marker of increased filling pressure of LV, as it is a hormone released by myocardial cells in volume overload setting. An important feature is that it can be detectable in a subclinical stage of HF and its value reflects HF severity. (Emdin et al., 2005) 
Thus it seemed reasonable to assume that BNP would be increased in patients with chemotherapy-induced cardiomyopathy. However, data currently available are heterogeneous. Some studies reported an elevation of BNP after treatment (Sandri et al., 2005; Pinchon et al., 2005), others obtained negative results (Sawaya et al., 2011). Therefore, the utility of BNP as a biomarker of cardiac damage induced by chemotherapy was not confirmed.

Larger, prospective trials are needed to elucidate BNP role in this setting.

\section{Treatment and prevention strategies}

Guidelines suggest HF standard therapy in patients with symptomatic or asymptomatic evidence of trastuzumab-induced cardiac dysfunction. However, as these patients have been excluded from almost all large randomized trials assessing the efficacy of HF treatment, there isn't definite evidence whether the long-term benefits of HF therapy can be directly transferred to this setting (Bovelli, 2010; Eschenhagen, 2011).

Nevertheless, data from adjuvant trials of trastuzumab and observational studies, such as the one conducted by Ewer et al (2005), support the use of HF therapy specially angiotensin converting enzyme inhibitors (ACEI) and beta-blockers.

Some other questions in this setting need to be addressed. Should we withdraw trastuzumab in patients who developed cardiotoxicity independently of the grade of LVEF impairment? Some authors proposed an evaluation scheme showed in Table 6, in which trastuzumab should be stopped in asymptomatic patients if LVEF declines more than 20 points from baseline or $\mathrm{LVEF}<30 \%$, and in symptomatic patients if LVEF reduces more than 30 points from baseline. And should we discontinue the drug in all patients who developed cardiotoxicity or just in high-risk patients? Based on results of the study by Cardinale et al. (2010) we can speculate that patients with normal value of TNI and reduction in LVEF could be maintained in trastuzumab therapy while receiving HF therapy and close monitoring. However we don't have yet a definite answer. Another important issue is, should we treat prophylactically high-risk patients? The data from Cardinale et al. (2006) suggest that early treatment with enalapril in patients with TNI positive after high-dose chemotherapy, prevent the development of cardiac dysfunction. (Fig. 7) Indeed, in those patients treated with ACEI, LVEF remained normal and compared with the untreated patients, a lower rate of adverse cardiac events was seen. (Table 6)

\begin{tabular}{lcccc}
\hline & Total $(\mathrm{n}=114)$, & ACEI Group $(\mathrm{n}=56)$, & Control Subjects $(\mathrm{n}=58)$, & \\
& $\mathrm{n}(\%)$ & $\mathrm{n}(\%)$ & $\mathrm{n}(\%)$ & $P$ \\
\hline Sudden death & $0(0)$ & $0(0)$ & $0(0)$ & $1.0^{\star}$ \\
Cardiac death & $2(2)$ & $0(0)$ & $2(3)$ & $0.49^{\star}$ \\
Acute pulmonary edema & $4(3)$ & $0(0)$ & $4(7)$ & $0.07^{\star}$ \\
Heart failure & $14(12)$ & $0(0)$ & $14(24)$ & $<0.001$ \\
Arrhythmias requiring treatment & $11(10)$ & $1(2)$ & $10(17)$ & 0.01 \\
Cumulative events & 31 & 1 & 30 & $<0.001$ \\
\hline
\end{tabular}

Reprinted from Cardinale, D. et al. (2006). Prevention of high-dose chemotherapy-induced cardiotoxicity in high-risk patients by angiotensin-converting enzyme inhibition. Circulation, Vol. 114, pp. 2474-2481

Table 6. Cardiac events in the study groups 


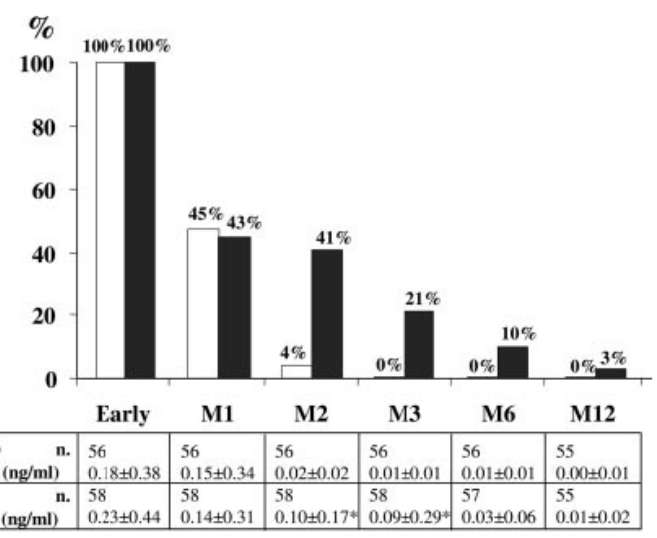

Reprinted from Cardinale, D. et al. (2006). Prevention of high-dose chemotherapy-induced cardiotoxicity in high-risk patients by angiotensin-converting enzyme inhibition. Circulation, Vol. 114, pp. 2474-2481

Fig. 7. Patients showing increased TNI value during follow-up in the ACEI group (open bars) and control subjects (solid bars). $\mathrm{P}<0.001$ (log-rank test). Mean \pm SD TNI values at each considered step are given at the bottom. ${ }^{*} \mathrm{P}<0.05$ vs ACEI group.

Kalay et al. (2006) studied the impact of prophylactic carvedilol use in patients receiving anthracycline chemotherapy and showed that LVEF maintained stable in those treated with beta-blocker, contrary to what occurred in the untreated group.

Probably the MANTICORE - Multidisciplinary Approach to Novel Therapies In Cardiology Oncology Research - trial, will add some light to this issue. This is a randomized, placebocontrolled trial that aims to determine if standard HF therapies can prevent trastuzumabinduced cardiotoxicity. (Pituskin, 2011)

\begin{tabular}{lllll}
\hline Physical status & LVEF & Trastuzumab & Monitor LVEF & $\begin{array}{l}\text { Therapeutic } \\
\text { guidelines }\end{array}$ \\
\hline Asymptomatic & $>50 \%$ & Continue & Repeat in 4 weeks & \\
& $\downarrow>10$ points but normal & Continue & Repeat in 4 weeks & Consider $\beta$ B \\
& $\downarrow 10-20$ points and LVEF $>40 \%$ & Continue & Repeat in 2-4 weeks & Treat CF \\
& $\downarrow>20$ points or LVEF $<30 \%$ & Suspend & If improved: surveillance & Treat CF \\
& & & If not improved/no change: stop & \\
& & & Repeat in 2 weeks & \\
& & & If improved $(>45 \%)$ : restart & \\
Symptomatic & $\downarrow<10$ points & Continue & If not improved/no change: stop & \\
& $\downarrow<10$ points and LVEF $>50 \%$ & Continue & Repeat in 2-4 weeks. & AnC? \\
& $\downarrow<30$ points & Stop & If improved/no change: & Treat CF \\
& & & surveillance & Treat CF \\
& & & If not improved: stop & \\
\hline
\end{tabular}

Adapted from Keefe DL. (2002). Trastuzumab-associated cardiotoxicity. Cancer, Vol. 95, pp. 1592-1600 $\downarrow=$ decrease; $\beta B=$ beta-blockers; $C F=$ cardiac failure; $L V E F=l$ eft ventricular ejection fraction; $\mathrm{NC}=$ noncardiac pathology. trastuzumab

Table 7. Proposal for the evaluation and treatment of heart failure in patients undergoin treatment with trastuzuma 
Some authors suggest other strategies to minimize cardiotoxicity (Sengupta, 2008), such as the adoption of non-anthracyclines regimes, to prefer larger intervals between the administration of anthracyclines and trastuzumab or to diminish the duration of trastuzumab adjuvant therapy. However, our conviction is that we should prompt effort in early diagnosis of cardiac dysfunction and appropriate treatment, in order to not deprive patients to a treatment with such substantial therapeutic benefits and propose the algorithm presented in Figure 8, for the management of patients receiving trastuzumab.

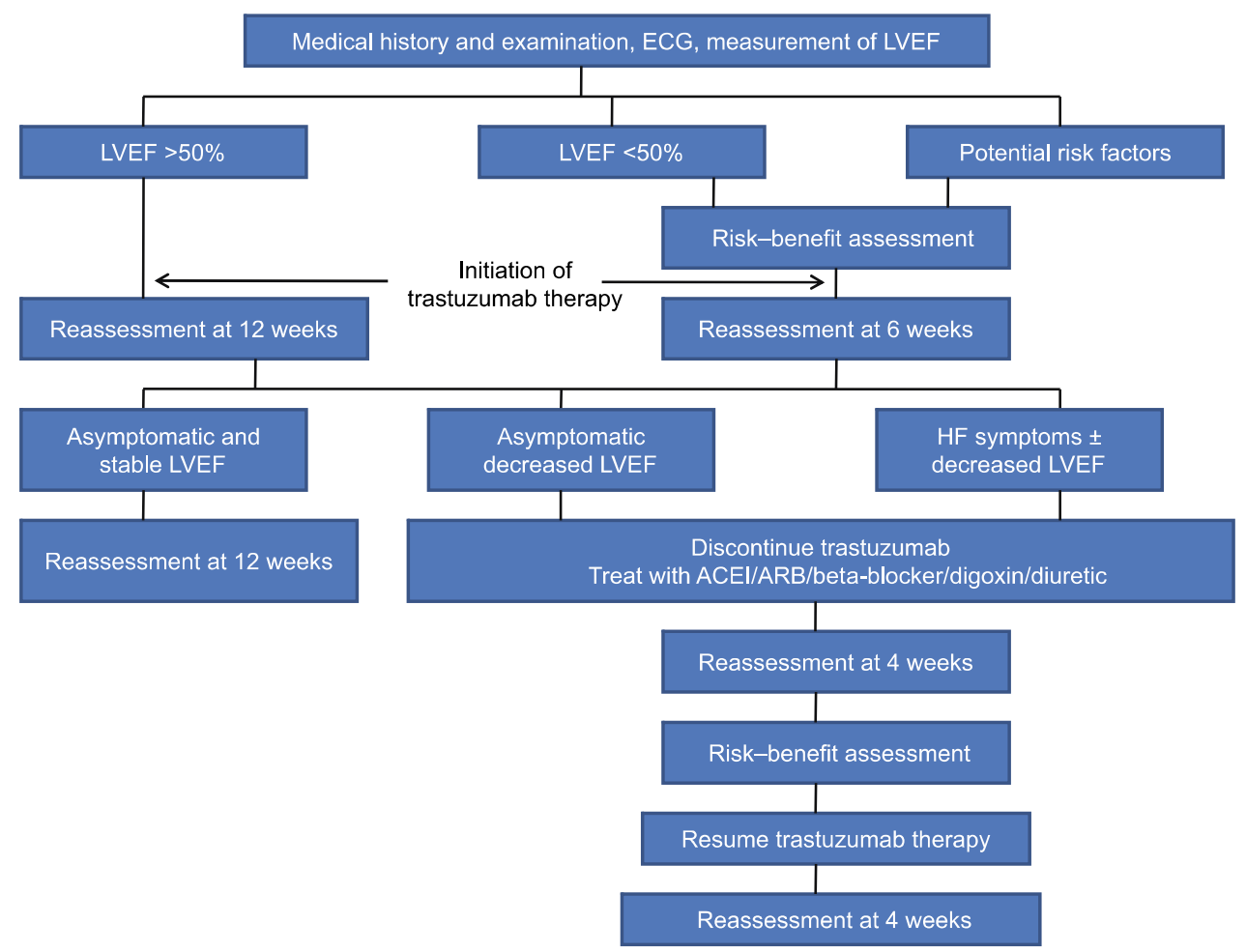

Abbreviations: ACEI, angiotensin-converting enzyme inhibitor; $\mathrm{ARB}$, angiotensin II receptor blocker; ECG, electrocardiography; HF, heart failure; LVEF, left ventricular ejection fraction (adapted from Martin M et al (2009);

Fig. 8. Proposed algorithm for the management of patients receiving treatment with trastuzumab.

\section{Conclusion}

Trastuzumab is the standard of care for treatment of patients with ERB2-positive breast cancer. When used in combination with chemotherapy, trastuzumab can improve overall survival in patients with ERB2-positive metastatic breast cancer and disease free survival and overall survival in patients with early ERB2-positive breast cancer. Because of the risk of cardiac dysfunction associated with trastuzumab therapy, cardiac function should be monitored closely (Carver, 2010). 
Cardiotoxicity has a strong impact on patients with cancer. This paradigm suggests that a multidisciplinar team of cardiologists and oncologists may provide a more comprehensive care to this complex patient population.

The main strategy is early detection of high risk patients and prompt prophylatic treatment. New echocardiographic methods to detect subclinical myocardial changes, measurement of cardiospecific biomarkers may become useful routine methods for identifying patients more prone to developing cardiotoxicity and in whom a preventive pharmacologic approach together with a closer cardiac monitoring could reduce a major cause of mortality in women with breast cancer.

\section{References}

Baselga, J.; Tripathy, D.; Mendelsohn, J. et al. (1996). Phase II study of weekly intravenous recombinant humanized anti-p185HER2 monoclonal antibody in patients with HER2/neu-overexpressing metastatic breast cancer. Journal of Clinical Oncology, Vol. 14, No.3, pp. 737-744

Billingham, M (1978). Use of the myocardial biopsy to monitor cardiotoxicity. Cancer Treatment Reports, Vol. 62, pp. 1607

Billingham, M.; Mason, J.; Bristow, M. \& Daniels JR. (1978). Anthracycline cardiomyopathy monitored by morphological changes. Cancer Treatment Reports, Vol. 62, pp. 865-72

Bovelli, D.; Plataniotis, G. \& Roila, F. (2010). Cardiotoxicity of chemotherapeutic agents and radiotherapy-related heart disease: ESMO Clinical Practice Guidelines. Annals of Oncology, Vol.21 (Supplement 5), pp. 277-282

Buzdar, I. (2005). Significantly higher pathological complete remission rate after neoadjuvant therapy with trastuzumab, paclitaxel, and epirubicin chemotherapy: results of a randomized trial in human epidermal growth factor receptor2-positive operable breast cancer. Journal of Clinical Oncology, Vol. 23, pp. 3676-85

Cardinale, D.; Sandri, M.; Colombo, A. et al. (2004). Prognostic Value of Troponin I in Cardiac Risk Stratification of Cancer Patients Undergoing High-Dose Chemotherapy. Circulation, Vol. 109, pp. 2749-2754

Cardinale, D.; Colombo, A.; Sandri, T. et al. (2006). Prevention of high-dose chemotherapyinduced cardiotoxicity in high-risk patients by angiotensin-converting enzyme inhibition. Circulation, Vol. 114, pp. 2474-2481

Cardinale, D.; Colombo, A.; Torrisi, R.; Sandri, M. et al. (2010). Trastuzumab-Induced Cardiotoxicity: Clinical and Prognostic Implications of Troponin I Evaluation. Journal of Clinical Oncology, Vol.28, No.25, pp. 3910-3916

Carver, J. (2010). Management of trastuzumab-related cardiac dysfunction. Progr Cardiovascular Disease, Vol. 53, pp. 130-139.

Chien, K. (2006). Herceptin and the heart-a molecular modifier of cardiac failure. New England Journal of Medicine, Vol. 8, pp. 789-790.

Cobleigh, M; Vogel, C.; Tripathy, D. et al. (1999). Multinational study of the efficacy and safety of humanized anti-HER2 monoclonal antibody in women who have HER2overexpressing metastatic breast cancer that has progressed after chemotherapy for metastatic disease. Journal of Clinical Oncology, Vol.17, No.9, pp. 2639-2648

Crone, S.; Zhao, Y.; Fan, L. et al. (2002). ErbB2 is essential in the prevention of dilated cardiomyopathy. Nature Medicine, Vol. 8, pp. 459-465 
Dolci, A.; Dominici, R.; Cardinale, D.; Sandri, M. \& Panteghini, M. (2008). Biochemical markers for prediction of chemotherapy-induced cardiomyopathy: systematic review of the literature and recommendations for use. American Journal of Clinical Pathology, Vol. 130, pp. 688-695

Emdin, M.; Clerico, A.; Clemenza, F. et al. (2005). Recommendations for the clinical use of cardiac natriuretic peptides. Italian Heart Journal, Vol.6, pp. 430-446.

Eschenhagen, T.; Force, T.; Ewer, M. et al. (2011). Cardiovascular side effects of cancer therapies: a position statement from the Heart Failure Association of the European Society of Cardiology. European Journal of Heart Failure, Vol. 13, pp. 1-10

Ewer, M.; Martin, F.; Henderson, I. et al. (2002). Cardiac safety of liposomal anthracyclines. Seminary Oncology, Vol. 31 (suppl 13), pp. 161-181.

Ewer, M.; Vooletich, M.; Valero, V. et al. (2002). Trastuzumab (Herceptin) cardiotoxicity: Clinical course and cardiac biopsy correlations. Proceedings American Society of Clinical Oncology. Vol.21, pp. 123

Ewer, M. \& Lippman, S. (2005). Type II chemotherapy-related cardiac dysfunction: time to recognize a new entity. Journal of Clinical Oncoloy, Vol. 23, No.13, pp. 2900-2902.

Ewer, M., Vooletich, M. et al. (2005). Reversibility of trastuzumab related cardiotoxicity: new insights based on clinical course and response to medical treatment. Journal of Clinical Oncology, Vol.23, No.31, pp. 7820-7826

Ewer, M. \& Ewer, S. (2010). Troponin I Provides Insight Into Cardiotoxicity and the Anthracycline-Trastuzumab Interaction. Journal of Clinical Oncology, Vol. 28, No. 25, pp 3901-3909

Ewer, S. \& Ewer, M. (2009). Anthracycline cardiotoxicity: why are we still interested? Oncology, Vol. 23, pp. 134-234

Ewer, S. \& Ewer, M. (2008). Cardiotoxicity profile of trastuzumab. Drug Safety, Vol.22, pp. 322-329

Fallah-Rad, N.; Lytwyn, M.; Fang, T.; Kirkpatrick, I. et al. (2008). Delayed contrast enhancement cardiac magnetic resonance imaging in trastuzumab induced cardiomyopathy. Journal of Cardiovascular Magnetic Resonance, Vol. 10, pp 5.

Feldman, A.; Koch, W. \& Force, T. (2007). Developing strategies to link basic cardiovascular sciences with clinical drug development: another opportunity for translational sciences. Clinical Pharmacology Therapy, Vol.81, pp. 887-92

Force, T.; Krause, D. \& Van, E. (2007). Molecular mechanisms of cardiotoxicity of tyrosine kinase inhibition. Nature Reviews Cancer, Vol. 7, pp. 332-344

Geyer, C.; Forster, J.; Lindquist, D. et al. (2006). Lapatinib plus capecitabine for HER2-positive advanced breast cancer. New England Journal of Medicine, Vol. 355, pp. 2733-2743

Geyer, H.; Caracciolo, G.; Abe, H.; Wilansky, S.; Carerj, S.; Gentile, F. et al. (2010). Assessment of Myocardial Mechanics Using SpeckleTracking Echocardiography: Fundamentals and Clinical Applications. Journal of American Society of Echocardiography, Vol. 23, No.4, pp. 351-69

Guarneri, V. e. (2006). Long-term cardiac tolerability of trastuzumab in metastatic breast cancer: the MD Anderson Cancer Center experience. Journal of Clinical Oncology,Vol. 24, pp. 4107-4115

Hare, J.; Brown, J.; Leano, R. \& Jenkins, C. (2009). Use of myocardial deformation imaging to detect preclinical myocardial dysfunction before conventional measures in patients undergoing breast cancer treatment with trastuzumab. American Heart Journal, Vol. 158, No. 2, pp. 294-301

Ho, C. \& Solomon, S. (2006). A Clinician's Guide to Tissue Doppler Imaging. Circulation, Vol.113, pp. 396-398 
Hutchins, L.; Unger, J.; Crowley, J. et al. (1999). Underrepresentation of patients 65 years of age or older in cancer-treatment trials. New England Journal of Medicine, Vol.341, pp. 2061-2067

Jassal, D.; Han, S.; Hans, C. et al. (2009). Utility of tissue Doppler and strain rate imaging in the early detection of trastuzumab and anthracycline mediated cardiomyopathy. Journal of American Society of Echocardiography, Vol. 22, pp. 418-24

Joensuu, H.; Kellokumpu-Lehtinen, P.; Bono, P. et al. (2006). Adjuvant docetaxel or vinorelbine with or without trastuzumab for breast cancer. New England Journal of Medicine, Vol. 354, pp. 809-820

Kalay, N.; Basar, E.; Ozdogru, I. et al. (2006). Protective effects of carvedilol against anthracycline-induced cardiomyopathy. Journal of American College of Cardiology, Vol. 48, No. 11, pp.2258-2262

Keefe, D. (2002). Trastuzumab-associated cardiotoxicity. Cancer, Vol. 95, pp. 1592-1600

Korte, M. ; Vries, E.; Lub-de Hooge, M. et al. (2007). 111Indiumtrastuzumab visualises myocardial human epidermal growth factor receptor 2 expression shortly after anthracycline treatment but not during heart failure: A clue to uncover the mechanisms of trastuzumab-related cardiotoxicity. European Journal of Cancer, Vol. 43, pp. 2046-2051

Lefrak, E.; Pitha, J.; Rosenheim, S. et al. (1973). A clinicopathologic analysis of adriamycin cardiotoxicity. Cancer, Vol. 32, pp. 302-314

Legha, S.; Benjamin, R.; Mackay, B. et al. (1982). Reduction of doxorubicin cardiotoxicity by prolonged continuous intravenous infusion. Annals of Internal Medicine, Vol. 96, pp. 133-139

Martin, M. (2009). Minimizing cardiotoxicity while optimizing treatment efficacy with trastuzumab: review and expert recommendations. The Oncologist, Vol. 14, pp. 1-11

Menendez, J. \& Lupu, R. (2007). Targeting human epidermal growth factor receptor 2: it is time to kill kinase death human epidermal growth factor receptor 3. Journal of Clinical Oncology, Vol.25, pp. 2496-2498

Negro, A.; Brar, B. \& Lee, K. (2004). Essential roles of Her2/erbB2 in cardiac development and function. Recent Progress in Hormone Research, Vol. 59, pp. 1-12

Neilan, T.; Jassal, D.; Perez-Sanz, T. et al. (2006). Tissue Doppler imaging predicts left ventricualr dysfunction in a murine model of cardiac injury. European Heart Journal, Vol. 27, pp. 1868-75

Ozcelik, C.; Erdmann, B.; Pilz, B. et al. (2002). Conditional mutation of the ErbB2(HER2) receptor in cardiomyocytes leads to dilated cardiomyopathy. Proceedings of the National Academy of Sciences, Vol. 99, pp. 8880-8885

Pai, V. \& Nahata, M. (2000). Cardiotoxicity of chemotherapeutic agents: incidence, treatment and prevention. Drug Safety, Vol. 22, No. 4, pp. 263 - 302

Perez, E. \& Rodeheffer, R. (2004). Clinical cardiac tolerability of trastuzumab. Journal of Clinical Oncology, Vol. 22, No.2, pp. 322-329

Piccart-Gebhart, M.; Procter, M.; Leyland-Jones, B. et al. (2005). Trastuzumab after adjuvant chemotherapy in HER2-positive breast cancer. New England Journal of Medicine, Vol.353, pp.1659-1672

Pichon, M.; Cvitkovic, F.; Hacene, K. et al. (2005). Drug-induced cardiotoxicity studied by longitudinal B-type natriuretic peptide assays and radionuclide ventriculography. In Vivo, Vol. 19, pp. 567-576

Pinder, M.; Duan, Z.; Goodwin, J.; Hortobagyi, G. \& Giordano, S. (2007). Congestive heart failure in older women treated with adjuvant anthracycline chemotherapy for breast cancer. Journal of Clinical Oncology, Vol. 25, pp. 3808-3815 
Pituskin, E. et al. (2011). Rationale and design of the Multidisciplinary Approach to Novel Therapies in Cardiology Oncology Research Trial (MANTICORE 101 - Breast): a randomized, placebo-controlled trial to determine if conventional heart failure pharmacotherapy can prevent trastuzumab-mediated left ventricular remodeling among patients with HER2+ early breast cancer using cardiac MRI. BMC Cancer, Vol. 11, pp. 318

Romond, E.; Perez, E.; Bryant, J. et al. (2005). Trastuzumab plus adjuvant chemotherapy for operable HER2-positive breast cancer. New England Journal of Medicine, Vol. 353, pp. 1673-1684

Sandri, M. ; Salvatici, M. ; Cardinale, D. et al. (2005). N-terminal pro-B-type natriuretic peptide after high-dose chemotherapy: a marker predictive of cardiac dysfunction? Clinical Chemistry, Vol. 51, pp. 1405-1410

Sawaya et al. (2011). Early detection and Prediction of Cardiotoxicity in Chemotherapytreated patients, American Journal of Cardiology, Vol. 107, No.9, pp. 1375-1380

Sawyer, D.; Zuppinger, C.; Miller, T. et al. (2002). Modulation of anthracycline induced myofibrillar disarray in rat ventricular myocytes by neuregulin-1_and anti-erbB2potential mechanism for trastuzumab-induced cardiotoxicity. Circulation, Vol. 105, pp. 1551-1554

Seidman, A.; Hudis, C.; Pierri, M. et al. (2002). Cardiac dysfunction in the trastuzumab clinical trials experience. Journal of Clinical Oncoloyg, Vol. 20, No. 5, pp. 1215 - 1221

Sengupta, P.; Northfelt, D.; Gentile, F. et al. (2008). Trastuzumab-induced cardiotoxicity: heart failure and crossroads. Mayo Clinic Proceedings, Vol. 83, No.2, pp. 197-203

Serrano, C.; Corte, J.; De Mattos-Arruda, L. et al. (2011). Trastuzumab-related cardiotoxicity in the elderly: a role for cardiovascular risk factors. Annals of Oncology

Slamon, D.; Clark, G.; Wong, S.; Levin, W.; Ulrich, A. \& McGuire, W. (1987). Human breast cancer: correlation of relapse and survival with amplification of the HER-2/neu oncogene. Science, Vol.235, pp. 177-82

Slamon, D.; Leyland-Jones, B.; Shak, S. et al. (2001). Use of chemotherapy plus a monoclonal antibody against HER2 for metastatic breast cancer that overexpresses HER2. New England Journal of Medicine, Vol. 344, No.11, pp. 783-792

Speyer, J. (2002). Cardiac dysfunction in the trastuzumab clinical experience. Journal of Clinical Oncology, Vol. 20, pp.1156-1157

Swain, S. \& Vici P. (2004). The current and future role of dexrazoxane as a cardioprotectant in anthracycline treatment: Expert panel review. Journal of Cancer Research and Clinical Oncology, Vol.130, pp. 1-7

Tan-Chiu, E. ; Yothers, G. ; Romond, E. et al. (2005). Assessment of cardiac dysfunction in a randomized trial comparing doxorubicin and cyclophosphamide followed by paclitaxel, with or without trastuzumab as adjuvant therapy in node-positive, human epidermal growth factor receptor 2-overexpressing breast cancer: NSABP B31. Journal of Clinical Oncology, Vol.23, No.9, pp. 7811-7819.

Valero, V.; Gill, E.; Paton, V. et al. (2004). Normal cardiac biopsy results following coadministration of doxorubicin, cyclophosphamide and trastuzumab to women with HER2 positive metastatic breast cancer. Journal of Clinical Oncoloy, Vol.22, pp. 572

Vogel, C. (2002). Efficacy and safety of trastuzumab as single agent in first-line treatment HER2- overexpressing metastatic breast cancer. Journal of Clinical Oncology, Vol. 20, pp. 719-26. 


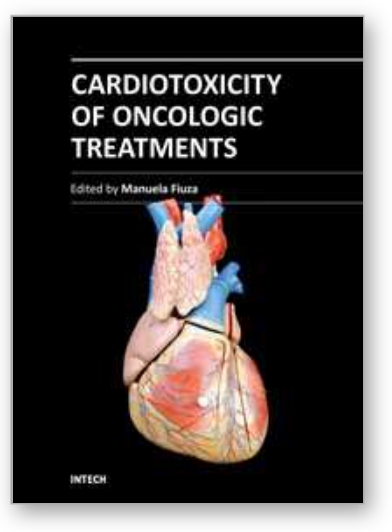

\section{Cardiotoxicity of Oncologic Treatments}

Edited by Prof. Manuela Fiuza

ISBN 978-953-51-0273-1

Hard cover, 194 pages

Publisher InTech

Published online 28, March, 2012

Published in print edition March, 2012

The possibility of getting a cardiovascular disease or cancer increases with advancing age. At the same time, relevant improvements in cancer therapy have resulted in the improvement of quality of life and the increasement of the survival rate of such patients. As a result we have larger number of patients that experience the cardiac side effects of chemotherapy. The extent of cardiotoxicity is variable, depending on the type of drug used, combination with other drugs, prior mediastinal radiotherapy and the presence of cardiovascular risk factors or history of heart disease. Early detection of the patients proneness for developing cardiotoxicity is the key issue to decrease morbidity and mortality. It also facilitates more tailored therapeutic interventions. Therefore, the collaboration and interaction of cardiology and oncology may contribute to reducing the cardiovascular adverse effects and improving the results in the treatment of patients with cancer.

\section{How to reference}

In order to correctly reference this scholarly work, feel free to copy and paste the following:

M. Fiuza and A. Magalhães (2012). Trastuzumab and Cardiotoxicity, Cardiotoxicity of Oncologic Treatments, Prof. Manuela Fiuza (Ed.), ISBN: 978-953-51-0273-1, InTech, Available from: http://www.intechopen.com/books/cardiotoxicity-of-oncologic-treatments/trastuzumab-and-cardiotoxicity

\section{INTECH}

open science | open minds

\author{
InTech Europe \\ University Campus STeP Ri \\ Slavka Krautzeka 83/A \\ 51000 Rijeka, Croatia \\ Phone: +385 (51) 770447 \\ Fax: +385 (51) 686166 \\ www.intechopen.com
}

\author{
InTech China \\ Unit 405, Office Block, Hotel Equatorial Shanghai \\ No.65, Yan An Road (West), Shanghai, 200040, China \\ 中国上海市延安西路65号上海国际贵都大饭店办公楼 405 单元 \\ Phone: +86-21-62489820 \\ Fax: +86-21-62489821
}


(C) 2012 The Author(s). Licensee IntechOpen. This is an open access article distributed under the terms of the Creative Commons Attribution 3.0 License, which permits unrestricted use, distribution, and reproduction in any medium, provided the original work is properly cited. 